\title{
Injecting a rapid rail link into a metropolis
}

\author{
J. P. du Plessis \\ Department of Construction Economics, University of Pretoria, \\ South Africa \\ South Africa and Commercial Advisor, Gautrain Rail Rapid Link, \\ South Africa
}

\begin{abstract}
The Gautrain Project being developed in the Gauteng province of South Africa is currently the largest construction project on the African continent. At an estimated cost of some US $\$ 3000$ million, it surpasses any previous single project in South Africa, and will result in a vital rapid rail link between Johannesburg, Pretoria and Johannesburg's OR Tambo International Airport. The total route length of $80 \mathrm{~km}$ will comprise some $15 \mathrm{~km}$ in tunnels in Johannesburg, about $10.5 \mathrm{~km}$ on viaducts along various sections of the route, and the balance on the surface or in shallow open cuts. The Gautrain is being developed by the Gauteng Provincial Government through a Public Private Partnership concession contract with an international consortium of major players in the construction, public transport vehicle manufacturing and operations fields. While construction will take place over a period of some four years to 2011, the Concessionaire will operate the full system for a further 15 years, after which the Province will assume the responsibility. With ten stations being built along the route, some in virtual green field surroundings and others in high density urban areas, and some deep underground and others using air rights above ground, profound land use challenges and opportunities arise. Superimposing a rapid rail artery of this magnitude onto the urban landscape of three metropolitan areas is bound to have considerable environmental and land use impacts. This paper demonstrates, at a critical stage in the civil construction programme, how these impacts are being addressed and how the natural and built environment is being considered and perhaps even enhanced, rather than being adversely affected.

Keywords: public transport, rapid rail, land use integration, transit oriented development, environmental impact.
\end{abstract}




\section{Background}

The Gautrain being developed in the Gauteng Province of South Africa is currently the largest construction project on the African continent. At an estimated cost of some US\$3000 million, it surpasses any previous single project in South Africa, and will result in a vital rapid rail link between Johannesburg, Pretoria and Johannesburg's OR Tambo International Airport. The total route length of $80 \mathrm{~km}$ will comprise some $15 \mathrm{~km}$ in tunnels in Johannesburg, about $10.5 \mathrm{~km}$ on viaducts along various sections of the route, and the balance on the surface or in shallow open cuts.

The project was officially announced in February 2000 as one of the Gauteng Provincial Government's ten 'Blue IQ' projects. These initiatives, of which most are in advanced stages of development or completed, were aimed at accelerated economic development and job creation in South Africa's smallest, but economically most important province.

\subsection{Gauteng in perspective}

The Gauteng Province in the northern part of South Africa is home to three of the country's important metropolitan areas, namely Johannesburg, Tshwane (Pretoria) and Ekurhuleni (comprising various cities east of Johannesburg). Of the nine provinces in South Africa, Gauteng is by far the smallest, but the most densely populated. Table 1 summarises some recent South African statistics by province.

Table 1: $\quad$ Provincial statistics [1].

\begin{tabular}{|c|c|c|c|c|c|c|c|c|}
\hline PROVINCE & \multicolumn{2}{|c|}{$\begin{array}{l}\text { SURFACE } \\
\text { AREA } \\
\text { x1000 }\end{array}$} & \multicolumn{2}{|c|}{ POPULATION } & \multicolumn{2}{|c|}{ WORKERS } & \multicolumn{2}{|c|}{$\begin{array}{l}\text { BUILDING } \\
\text { PLANS PRIV } \\
\text { SECTOR } \\
\text { USS }\end{array}$} \\
\hline EASTERN CAPE & 169.6 & 13.9 & 6579.3 & 13.5 & 1491.0 & 11.3 & 449.0 & 5.0 \\
\hline FREESTATE & 129.5 & 10.6 & 2877.7 & 5.9 & 831.0 & 6.3 & 263.7 & 2.9 \\
\hline GAUTENG & 17.0 & 1.4 & 10447.1 & 21.5 & 3821.0 & 28.9 & 3942.0 & 43.6 \\
\hline KWAZULU NATAL & 92.1 & 7.6 & 10105.5 & 20.8 & 2285.0 & 17.3 & 1335.7 & 14.8 \\
\hline LIMPOPO & 123.9 & 10.2 & 5274.8 & 10.8 & 868.0 & 6.6 & 184.0 & 2.0 \\
\hline MPUMALANGA & 79.5 & 6.5 & 3590.0 & 7.4 & 983.0 & 7.4 & 408.9 & 4.5 \\
\hline NORTHERN CAPE & 361.8 & 29.7 & 1125.1 & 2.3 & 304.0 & 2.3 & 76.5 & 0.8 \\
\hline NORTH WEST & 116.3 & 9.5 & 3425.0 & 7.0 & 850.0 & 6.4 & 330.2 & 3.6 \\
\hline WESTERN CAPE & 129.4 & 10.6 & 5262.0 & 10.8 & 1800.0 & 13.6 & 2058.5 & 22.8 \\
\hline TOTALS & 1219.1 & 100.0 & 48686.5 & 100.0 & 13233.0 & 100.0 & 9048.5 & 100.0 \\
\hline
\end{tabular}

While the Gauteng Province comprises only 1.4 percent of South Africa's surface area, it is home to some 21.5 percent of the population, supplies work to almost 30 percent of the labour force and accounts for virtually half of the private sector building activity. (Adding Government building investment will increase this contribution to well over 50 percent.) The three metropolitan areas 
in Gauteng are highly industrialised, with a well developed transport system for road and rail traffic, including extensive urban freeway systems, metropolitan bus networks and a rail network for freight and passenger transport.

\subsection{Travel demand and need for a rapid rail system}

Vehicle ownership in South Africa has increased sharply in the past two decades, in line with accelerated socio-economic development of many of its citizens. This places heavy demands on the transportation systems, and in particular the road systems, in the light of lower than ideal levels of rail freight and rail patronage. While Wegener and Fürst [2] argue that trip length should be negatively correlated with city size, metropolitan freeways in Gauteng have become heavily congested, filled with long trips and resultant travel times that are beyond what should be tolerable in South Africa.

The 2010 FIFA World Cup is to be hosted by South Africa. In preparation for this event, major infrastructure programmes are underway, including various new and enlarged sport stadiums, freeway and other road improvement programmes, bus rapid transit (BRT) systems in different metropolitan areas, to name but a few. In the Gauteng province, where many of the World Cup games including the opening and closing games will take place, the National Roads Agency is currently improving about 145 route kilometres of freeway at a cost much in excess of US\$1000 million. Given even all of the planned road improvements, a major shortcoming in the bigger metropolitan transport framework, has been the lack of a high capacity public transport facility to cater for travel demand between important activity nodes in Gauteng. The Gautrain Rapid Rail Link is expected to address this shortcoming.

\section{The project in brief}

\subsection{The contract}

The Gautrain is being constructed as a Public-Private Partnership development in two major phases in the metropolitan areas of Johannesburg, Ekurhuleni and Tshwane (Pretoria). After a very extensive planning and bidding process between 2000 and 2006, the project was awarded to an international consortium consisting mainly of Bombardier (Canadian), Bouygues Travaux Publics (French), Murray \& Roberts (South African), Strategic Partners Group (South African) and RATP Développement (French). The private partner consortium, called Bombela Concession Company, has entered into a 19.5 year concession agreement with the Gauteng Provincial Government for the design and construction ( 4.5 years) and the operation and maintenance (15 years) of the system. A total of 24 train sets, operating at 10 minute headways, will be used in conjunction with some 125 buses in feeder/ distribution services around stations.

\subsection{The route}

Figure 1 gives a schematic layout of the system. It starts in Johannesburg at an underground station next to the existing main Park railway station. It runs north 
in a tunnel to the development hub of Sandton, passing the development hub of Rosebank, also with an underground station. North of Sandton the tunnel ends at Marlboro, with an at-grade station before the line splits in east-west and northsouth alignments. The east-west alignment continues via at-grade and viaduct sections to Johannesburg's OR Tambo International Airport, with an end station above ground in the terminal building. The north-south alignment traverses an extensive maintenance depot area, before continuing to the development centres of Midrand and Centurion to Pretoria's main railway station, and then onwards alongside the main rail line to end at Hatfield Station.

\subsection{Construction cost, programme and current status}

The total approved contract value is approximately 25000 million South African Rand (about US\$3000 million, depending on exchange rate fluctuations). The bulk of the funding - around 88 percent - is from Government, with the balance being Private Sector debt, while the Concessionaire will carry operating costs.

The Concession Agreement was signed in September 2006, with the intention for Phase 1 to be operational by mid 2010, with final completion in 2011. Phase 1 comprises the section between Sandton Station and the OR Tambo International Airport, including the maintenance depot, while the balance of the route south to Park Station and north to Pretoria and Hatfield Stations will form Phase 2. Although operational readiness of Phase 1 in time for the FIFA World Cup has never been a contractual requirement, all parties appreciate that this would be highly advantageous, and steps are being taken to investigate this possibility.

\section{Scale: Park Station to Hatfield $\approx 60 \mathrm{~km}$}

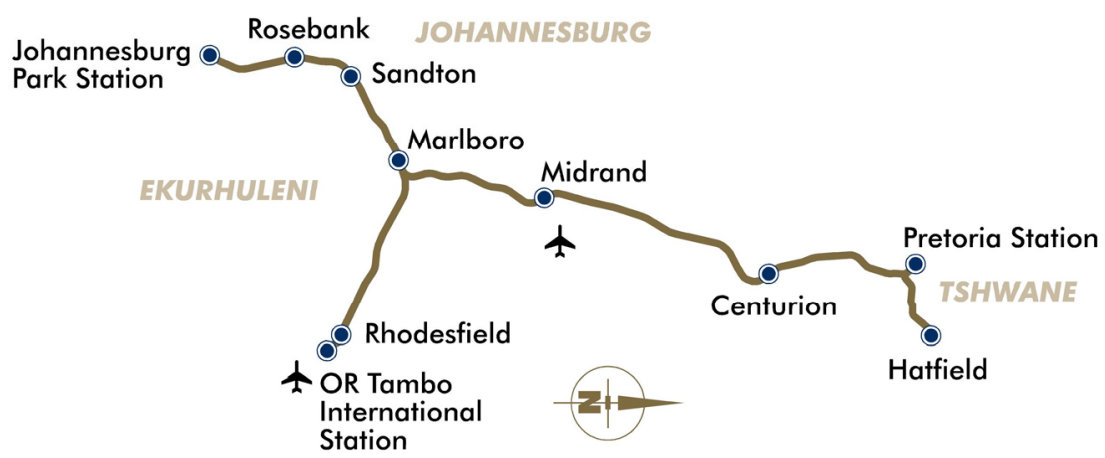

Figure 1: Schematic layout of the Gautrain Rapid Rail Link route.

At the time of preparing this paper - March 2009 - civil construction of the System was well advanced with about 75 percent of the work completed, while the electrical mechanical work, including track laying and appurtenant works was about 50 percent complete [3]. The first train sets manufactured in Derby in England have been assembled and shipped to site, while continuous progress is 
being made regarding local manufacturing of the balance of the 24 train sets in Ekurhuleni. Figures 2 and 3 give an indication of salient features currently under construction.

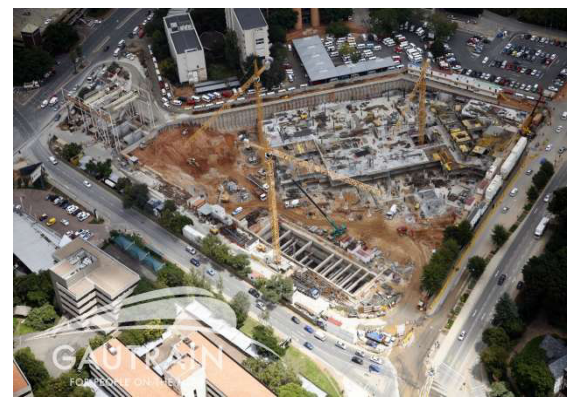

Figure 2: Sandton station.

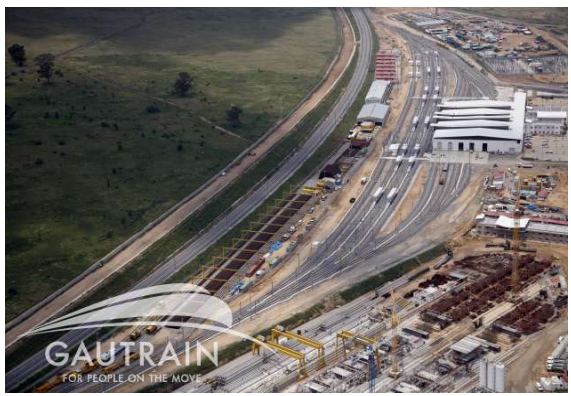

Figure 3: The maintenance depot.

\section{Integrating Gautrain with its environment}

\subsection{Development objectives}

The Gautrain project is part of the strategic development goals of the Gauteng Province. It also meets the needs and requirements reflected in the National Land Transportation Transition Act of 2000, which requires Government to prioritise and promote public transport and to improve the image of public transport. Thus, already in 2001, the following were some of the objectives approved for Gautrain [4]:

- to stimulate economic growth, development and job creation;

- to reduce severe traffic congestion in the Tshwane - Johannesburg corridor;

- to promote the use of public transport;

- to contribute significantly towards urban restructuring, shortening of travel distances and improving city sustainability; 
- to stimulate the renovation and upliftment of the Johannesburg and Tshwane Central Business Districts;

- to link the main economic nodes in Gauteng; and

- to comprise a significant part of a holistic transport plan and network for Gauteng.

The above presupposes a considerable degree of sustainable integration of Gautrain into Gauteng Province's transport system, economic development activities and natural environment. This was also a key requirement for the approval of the project by Government and is in line with current global thinking concerning successful integration of land use and transportation (See Hine [5]).

Densification of land uses near rapid transit routes and stations has for the past few decades been a prime objective of authorities on different continents. Stockholm was one of the first cities to link new town development with guided transit planning. Others, like Toronto, Hong Kong (with high government control over land), Lille Metropole, Edinburgh, Atlanta (MARTA), Auckland and recently Shanghai, are some examples of application of the principles of socalled Transport Development Areas (TDAs).

South African metropolitan development has followed the North American pattern of ever increasing urban sprawl and great reliance on the motor vehicle. Any opportunity to turn this tide towards increased densities and transit usage is to be actively pursued.

\subsection{Land use and modal integration around stations}

In pursuance of integrated land use planning at stations, the Province embarked on an initiative with the local municipalities to develop functional area guidelines to supplement local spatial development frameworks in the vicinities of the respective Gautrain stations. The development of areas within a one kilometre radius of stations was considered, with a view to:

- creating or reinforcing densities;

- $\quad$ promoting ridership (getting people to stations);

- $\quad$ establishing mixed land use around stations, thus with varying travel patterns throughout the day;

- $\quad$ ensuring appropriate and high density land use;

- $\quad$ establishing new urban form that embraces the Gautrain; and

- $\quad$ establishing integrated public transport nodes.

In most instances Urban Development Frameworks, taking full cognisance of the Gautrain stations and their impact on land use, have been completed and are being implemented. In the case of the Midrand Station, it was decided to relocate the route and station and to integrate these into a large future commercial development. At Modderfontein, on the airport link, the planning and construction of the Gautrain system provides for a major future new urban development, including a city centre with extensive commercial land uses. This is much in line with the TDA concept in North America, with major efforts to direct urban growth to infill sites and new suburban communities [5]. 
The station precincts obviously present superb opportunities for commercial development and it is thus not surprising that land use applications in excess of an estimated two million square metres of new development are being considered, representing potential capital investment in excess of the construction price of the entire Gautrain project in the next decade alone.

Physical integration with other modes of travel has received attention during the planning of the Gautrain stations. In addition to the integration afforded by the system's own feeder/distribution bus service to and from stations, it was required to give special attention to ensure convenient transfers to alternative rail operated by the South African Rail Commuter Corporation (SARCC) or other transport modes, where applicable:

- Johannesburg Park Station - The area around this station accommodates a wide range of transportation systems and comprises the interchange between the various systems, including long distance and cross-border passenger rail services, rail commuter services, long distance coach services, bus and minibus taxi's, and metered taxi services. The various parties involved have given substantial attention to physical interfaces between the 15 metre deep Gautrain station and its surroundings.

Sandton Station - Through an extensive process of consultation and cooperation between the Province and the City of Johannesburg, a Transit Oriented Development (TOD) was conceived and planned. The site is to be developed in two phases, the first being directly related to the 40 metre deep Gautrain station and comprising all underground station elements, a three-basement parking structure, public transport interchange at ground level and a podium above, linked to commercial developments in the vicinity, including Nelson Mandela Square. The second phase will consist of high density mixed use development above the podium and around a central public square.

- At Pretoria, Hatfield and Rhodesfield Stations the opportunities to transfer directly between SARCC and Gautrain lines have been seized, allowing expansion of the geographic area served by Gautrain.

Figures 4 and 5 give an impression of some of the facilities planned at various stations, in an effort to integrate with the surrounding urban fabric.

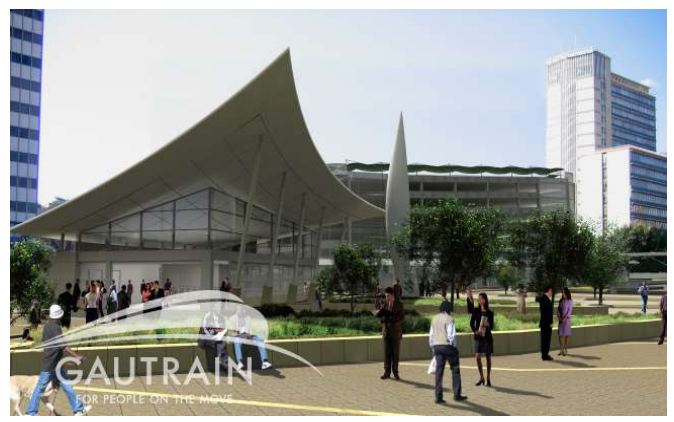

Figure 4: Park station. 


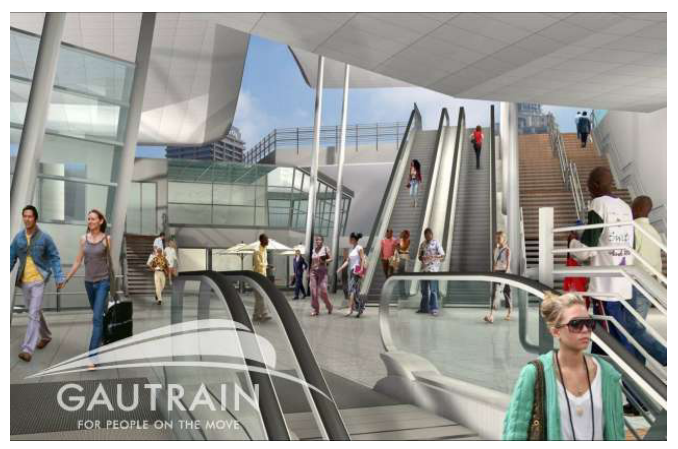

Figure 5: $\quad$ Sandton station with bus transit facility.

\subsection{Environmental integration}

\subsubsection{Legislative framework}

Environmental concerns regarding physical development in South Africa are regulated, inter alia, by the National Environmental Management Act (Act 107 of 1998) and the Environment Conservation Act (Act 73 of 1989). The Gauteng Department of Agriculture, Conservation and Environment (GDACE), acts as provincial implementers of these acts. GDACE issues Records of Decision (RoD's), approving or disallowing projects or aspects thereof, based on Environmental Impact Assessments (EIA's). The RoD on the proposed Gautrain Rapid Rail Link contained a series of conditions including the formulation and approval of an Environmental Management Plan (EMP) that will govern design, construction of, and ultimately operations and maintenance activities on the rail system. The conditions further stipulate that the EMP must be developed in a sequential manner through an iterative process.

A Draft Final EMP - the document that provides a description of the methods and procedures for mitigating and monitoring impacts and containing environmental objectives and targets in order to reduce or eliminate negative impacts - formed part of the Concession Agreement. The measure of EMP compliance is the subject of regular audits by independent parties.

\subsubsection{Environmental impact in practice}

Naturally, the most visible impact of such mammoth project is likely to be the civil construction work. Building operations are bound to be disruptive at times, with very visible impacts on the environment, including large earth embankments or cuts, numerous large, very busy construction sites and the like. Furthermore, noise pollution during construction (e.g. vehicle or equipment noise and blasting) has to be kept to within acceptable limits, particularly in or close to affluent residential and business areas. The Draft Final EMP contains strict measures to which the Concessionaire must adhere in order to keep adverse environmental impact during construction to a minimum. Even a small earth spillage into a natural water stream has brought the wrath of the relevant 
authorities onto the Concessionaire, as did fuel leakages, effluent water spills and other incidents.

On a broader level, several occasions arose during the planning and design of the system when very positive environmental impacts resulted. Examples are:

- Near Marlboro Station, where the line is on viaduct, increasing the viaduct spans obviated the need for deviation of a very large sewer main, which could have posed a major environmental risk.

- The route through Centurion was originally planned to be in a tunnel. Dolomites in the area prompted an alternative alignment on viaduct, which does have a visual impact, but was considered preferable to the risks associated with tunnelling through dolomites. Furthermore, a Water Management Plan regulates the handling of storm water from the system throughout the dolomite area, to reduce runoff into the dolomite substrata.

- North of Centurion, an at-grade U-shaped reinforced concrete structure is used across an area of varying geological nature to reduce the adverse impact the rail line could have had in an area of deep dolomites.

- In a part of the tunnel section where geotechnical investigations indicated extremely variable rock conditions, it was decided to employ a Tunnel Boring Machine (TBM) which was imported from Germany to drill and place the lining to some three kilometres of tunnel under Johannesburg. Even at additional equipment cost of some US\$40 million the use of the TBM was considered worthwhile, given the risks of disturbance in the rock formations with drill and blast methods. At the time of writing this paper, the TBM had completed its section of the tunnel and had been dismantled and the inner sections removed. The shell of the TBM is retained underground and will become part of the tunnel.

- Naturally all of the cut and fill slopes in the formation are being landscaped and grassed as soon as civil construction allows this, to limit the impact on the physical environment.

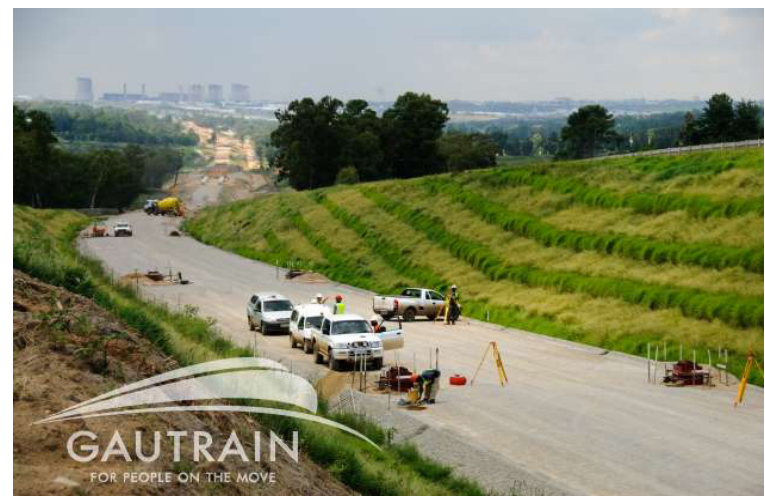

Figure 6: Track alignment and grassing of slopes. 




Figure 7: $\quad$ Viaducts across a natural stream and a major sewer line.

- Concerning noise and vibration, the specification for the system has very strict international compliance standards, and where these standards could not normally be attained at rail reserve edge, noise barriers and/or vibration dampening pads are used to mitigate any adverse effects.

Figures 6 and 7 below show examples where particular types of environmental concerns had to be addressed.

\section{A glimpse into the future}

The Gautrain is the first of its kind, not only for South Africa, but for the entire African continent. More systems such as this one have to, and will follow. Furthermore, the Gautrain system will have to expand in future, and provision is made in the planning and design of the system to extend the southern, northern and eastern ends, should the demand warrant this.

South west of Johannesburg lies the large city of Soweto, which has, until recently, been predominantly a dormitory city. During the past few years this city has seen major acceleration in commercial and industrial development, and it is conceivable that Gautrain should in future serve this hub as well. At its northern end, it is conceivable that the rapid rail link will in future be extended to connect to urban hubs with high development potential, such as the Menlyn area in Tshwane. Also at the airport end of the line the design allows for extension to a future midfield air terminal and to other cities east of Johannesburg.

With tremendous densification around the Gautrain stations, urban form in the Gauteng province will be transformed. New population concentrations will create demand for goods and services on a scale that will see the birth of several new cities along the rapid rail route. Modderfontein and Midrand are relative green field areas at present. In the near future these will become highly urbanised as a result of the rapid rail line. Trips to work have traditionally been very long for certain population groups due to settlement policies of the past. New residential and work opportunities, not only in new cities, but in the greater metropolis served by Gautrain, will tend to shorten work trips, to great advantage of those who will seize the opportunity. 


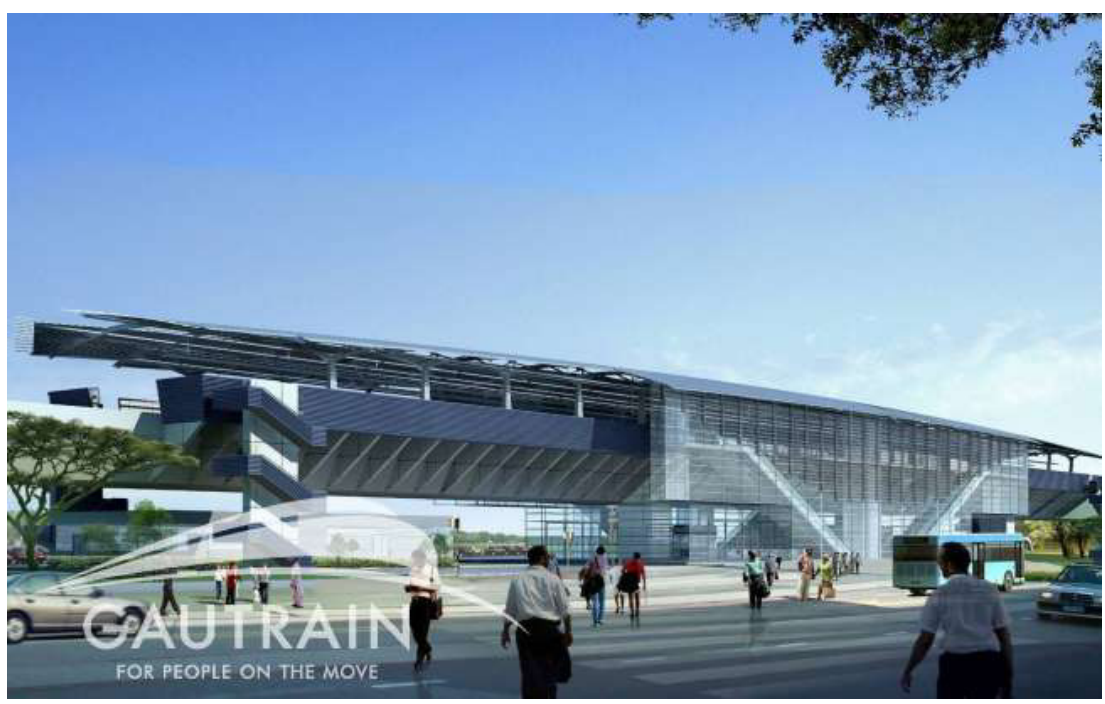

Figure 8: Centurion Station - integrated with bus transit.

Combined with the Gautrain there is enormous current investment in bus systems and improved road capacity, from urban street to freeway level. The different BRT systems currently being implemented in Gauteng are in line with advanced systems on different continents, such as the East Bay Bus Rapid Transit [6], scheduled to be operational in 2011. Johannesburg's BRT "Rea Vaya - we are moving" is expected to transport 430000 passengers daily along mostly dedicated lanes across the city and is said to be the main catalyst by which to achieve a 70:30 ratio of public transport to private transport ahead of 2010, according to Creamer [7]. Some 750 buses will operate on 120 kilometres of routes in phase 1, with 150 bus stations, integrating with Gautrain at Park, Rosebank and Sandton Stations. This and other similar systems in adjacent cities in Gauteng, together with the rail rapid system being injected in their midst, will indeed change travel patterns and the entire urban fabric of the region in years to come. Being fully compliant with the ideals and principles of the national Department of Transport's long term strategy [8], Gautrain is bound to be a catalyst in bringing about the desired outcomes of the national strategic action plan.

It has been written, even of modern day Los Angeles by Maisel [9], that "this amorphous skein of strip malls and gated developments, highway entrance and exit ramps, lies unfurled over the landscape like a sheet over a cadaver. Surely the earth is dead beneath the sheer weight and breadth of this built form?" Interventions such as the Gautrain Rapid Rail System will hopefully aid in bringing new life and vigour to the Gauteng metropolis that is not only the financial hub of South Africa, but indeed of Africa. It will have to take its place amongst the modern metropolitan regions of the world in years to come, and is on course to be up to the challenge. 


\section{References}

[1] Department of Statistics. Statistics South Africa, various quarterly and annual publications, www.statssa.gov.za

[2] Wegener, M. \& Fürst, F., Land-use Transport Interaction: State of the Art, 4th RTD Framework Programme of the European Commission, Dortmund University, p viii, 1999.

[3] Bombela Concession Company. Monthly progress report, February 2009.

[4] Gauteng Provincial Government. Gautrain Annual Report, 1 April 2007 - 31 March 2008.

[5] Hine, P., Integrating transport and development, Royal Institution of Chartered Surveyors Leading Edge Series, pp. 1-19, 2001.

[6] Alameda-Contra Costa Transit District, East Bay Bus Rapid Transit, A State-of-the-Art Transit Service for the Future, Rapid, Spring 2007, www.actransit.org.

[7] Creamer Media's Engineering News Online, 18 March 2009, www.engineeringnews.co.za.

[8] Department of Transport, Moving South Africa: A Transport Strategy for 2020, May 1999, www.transport.gov.za/projects/msa/msa.html.

[9] Maisel, M., Sanctuary and the Modern Metropolis, Orion Magazine Web Exclusive, January/February 2007, www.orionmagazine.org. 